\begin{tabular}{|l|l|}
\hline $\begin{array}{l}\text { ESCOLA DE COMUNICAÇÃO, } \\
\text { ARTES E DESIGN }\end{array}$ & $\begin{array}{l}\text { mídia, cultura e tecnologia } \\
\text { Revista FAMECOS, Porto Alegre, v. 28, p. 1-15, jan.-dez. } 2021 \\
\text { PUCRS }\end{array}$ \\
$\begin{array}{l}\text { FAMECOS } \\
\text { e-ISSN: 1980-3729 | ISSN-L: 1415-0549 }\end{array}$ \\
\hline https://dx.doi.org/10.15448/1980-3729.2021.1.41576
\end{tabular}

SEÇÃO: CINEMA

\title{
Presencia de mujeres inmigrantes latinoamericanas en el cine español
}

\author{
Presença de mulheres imigrantes latino-americanas no cinema espanhol \\ Presence of Latin-American immigrant women in Spanish cinema
}

\author{
Renata Barreto Malta ${ }^{1}$ \\ orcid.org/0000-0002-7414-9081 \\ renatamaltarm@gmail.com
}

\section{Inmaculada Gordillo orcid.org/0000-0002-9090-5166 ingoal@us.es}

Recebido em: 19 ago. 2021. Aprovado em: 13 out. 2021. Publicado em: 16 nov. 2021.
Resumen: El objetivo del artículo es analizar la presencia de la mujer inmigrante latinoamericana en el cine español a partir de un corpus compuesto por películas producidas entre 1999-2012. Se utilizaron herramientas metodológicas del Análisis de Contenido y la discusión teórica está basada en los Estudios Culturales, la Narrativa Audiovisual y los Estudios de Género. Los resultados indican que la presencia de esas personajes es efectiva, pero que se construye con bases hegemónicas en lo que concierne a nacionalidad, etnia y franja etaria. Además, se ha constatado que hay un predominio de argumentos centrados en la cotidianidad y la marginalidad.

Palabras clave: Cine español. Inmigración. Mujer latino-americana. Análisis de Contenido.

Resumo: O objetivo deste artigo é analisar a presença da mulher imigrante latino-americana no cinema espanhol a partir de um corpus composto por filmes produzidos entre 1999-2012. Foram utilizadas ferramentas metodológicas da Análise de Conteúdo e a discussão teórica está baseada nos Estudos Culturais, na Narrativa Audiovisual e nos Estudos de Gênero. Os resultados indicam que a presença dessas personagens é efetiva, mas que se constrói com bases hegemônicas no que concerne à nacionalidade, etnia e faixa etária. Ademais, foi constatado que há um predomínio de argumentos centrados na cotidianidade e na marginalidade.

Palavras-chave: Cinema espanhol. Imigração. Mulher latino-americana. Análise de Conteúdo.

Abstract: This article aims to investigate the presence of the Latin-American
immigrant woman in the Spanish cinema, based on an extensive corpus of films
within the period 1999-2012. Thus, it has been applied methodological tools of
Content Analysis and the theoretical discussion is grounded on Cultural Studies,
Audiovisual Narrative and Gender Studies. The results indicate that the presence
of those women is effective, even as main characters, but constituted by hege-
monic bases regarding nationality, ethnicity and age range. Furthermore, it has
been verified that there is a predominance of drama as a cinematographic genre,
centered on quotidian plot and marginality. Keywords: Spanish cinema. Immigration. Latin-American Women. Content Analysis.

\section{(c) (1)}

Artigo está licenciado sob forma de uma licença Creative Commons Atribuição 4.0 Internacional. 


\section{Introducción}

A partir de 1990 España empieza a recibir inmigrantes de forma regular y con un crecimiento progresivo hasta la llegada de la crisis que se inició en 2008. En paralelo, los estudios sobre la imagen de los inmigrantes en el cine español empiezan a proliferar por estas fechas, aumentando significativamente en la primera década del siglo XXI. Más allá de estudios de caso de títulos cinematográficos que abordan la temática "inmigración"-organizando un género propio de narrativas de la inmigración- y sus miradas especificas (TEIXEIRA, 2014; NAIBOGLU, 2017, entre otros), otras investigaciones presentan un panorama más general acerca de esas representaciones. Los parias de la tierra. Inmigrantes en el cine español, de Chema Castiello, ilustra ese intento al buscar "desentrañar el modelo o los modelos de representación del emigrante en el cine español" (CASTIELLO, 2005, p. 17) a partir del estudio del "otro", con un acercamiento a los realizadores/as que abordan la migración, una revisión de actores y actrices que encarnan a los inmigrantes y un análisis de las historias narradas. Por su parte, Eduardo Moyano en $\mathrm{La}$ memoria escondida. Emigración y cine (2005) analiza numerosas películas españolas para tratar temas como la emigración de los españoles, la inmigración de los "otros", el paro, el racismo y la memoria. También Santaolalla (2005), en su obra Los "otros". Etnicidad y raza en el cine español contemporáneo revisa los conceptos de raza y etnia y analiza la representación de la "otredad étnica" en el cine español.

En su tesis, Cavielles-Llamas (2008, p. 148) afirma que "el cine sobre inmigración en España es un género joven pero que en poco menos de dos décadas ha evolucionado en paralelo a la sociedad de la que es producto". Así, el autor traza fuertes conexiones entre la pantalla y el "mundo de la vida" (HABERMAS, 1981). En sus conclusiones, Cavielles-Llamas habla de una evolución en las producciones españolas que reflejan la figura del inmigrante extranjero hacia una visión más amplia e integradora, incluyendo una imagen de España no solo como "zona de paso", sino como nación pluriculturaly multiétnica que "cimente sólidas bases para la convivencia" (2008, p. 148).

Otros estudios tratan los profundos cambios culturales impulsados por la presencia de la inmigración en España y sus repercusiones en las producciones cinematográficas. "Esas relaciones de interculturalidad argumentales pueden ser tanto el reflejo de la realidad extracinematográfica [...] como la constitución de un modelo representacional que influya individual y socialmente en el espectador" (GORDILLO, 2006, p. 208). En este artículo se demuestra que el cine español de estas primeras etapas de acogida mostraba relaciones interculturales deficientes entre el oriundo y el inmigrante que llega huyendo de la pobreza, debido -sobre todo- a la mirada etnocéntrica y a los prejuicios sociales y culturales.

Para contemplar las desigualdades que estructuran esas relaciones de interculturalidad en la vida y en el cine español es relevante contemplar las marcas del colonialismo, especialmente cuando esas relaciones se construyen con países de América Latina, foco de la presente investigación. Hablar de colonialismo no significa una mirada hacia el pasado. De hecho, entendemos que el "poscolonialismo" no contempla rupturas, pero sí una "reescritura descentrada, diaspórica o 'global' de las grandes narrativas imperiales del pasado, centradas en la nación. Su valor teórico, por lo tanto, recae precisamente sobre el rechazo de una perspectiva del 'aqui' y 'allá', de un 'entonces' y 'ahora', de un 'en casa' y en 'el extranjero'" (HALL, 2003, p. 109. Traducción propia).

El concepto nos ayuda a describir el cambio de la era de los Imperios en el momento de la descolonización. Ese proceso ha marcado de forma intensa tanto a las metrópolis como a las colonias, siempre con caracteristicas jerárquicas y desiguales. Una investigación sobre la presencia de mujeres inmigrantes latinoamericanas en el cine español requiere, no solamente la premisa de la no superación del colonialismo - o especificamente la "colonialidad del género" (LUGONES, 2008), inscrita en las relaciones de poder vigentes- sino también la búsqueda de 
nuevas epistemologias decoloniales que ofrezcan puntos de vista alternativos al producir y validar el propio conocimiento (COLLINS, 2002, p. 298), "rechazando la continuidad de prácticas epistemicidas" (FIGUEIREDO, 2020, p. 5).

La inmigración latinoamericana presente en el cine español raras veces es el foco de atención de las investigaciones en torno a esta temática. De hecho, en la revisión bibliográfica hallamos un único artículo centrado en este punto $y$, aunque no se concentre en producciones del cine, posee hallazgos interesantes. Su conclusión apunta hacia un vacío entre realidad y la representación mediática, posicionando al inmigrante latinoamericano en una escala social menor, con una imagen más veces negativa que positiva y una presencia minoritaria en los media, comparada con su importancia real en la población española. (MUÑIZ et al., 2007).

Justo en esta parcela nos situamos para la trayectoria teórica y empírica de nuestra investigación. Aparte de la nacionalidad, nuestra atención se dirige a cuestiones de género y sus intersecciones con raza, etnia y rango etario, esferas que los estudios de campo no suelen diferenciar al analizar la representación del inmigrante en el cine español. Así, utilizando como método el Análisis de Contenido (BARDIN, 2009) desde una perspectiva cuantitativa, y con una reflexión cualitativa de los resultados, nuestro objetivo es acotar la presencia y perfil de la imagen de la inmigrante latinoamericana en el corpus elegido. Intuitivamente, su presencia puede resultar muy diferente (en cuestiones numéricas y por características definitorias) a la del conjunto de inmigrantes de forma general.

Para la interpretación de los resultados proponemos una discusión teórica basada en autores de los Estudios Culturales, de la Narrativa Audiovisual y de los Estudios de Género. Acerca de este último campo, aunque exista un predominio del modelo hegemónico eurocéntrico de pensar intelectualmente las relaciones de género, observamos la emergencia de otras reflexiones que moldean una producción creciente de conocimiento teórico contrahegemónico que no recae en la repetición de la colonialidad y reconoce la relevancia de intersecciones asociadas a las esferas de etnia, raza, clase y nacionalidad, que serán fundamentales para este estudio.

\section{Metodología}

Además de la revisión bibliográfica de autores que puedan contribuir al estudio, proponemos un camino empírico como eje central de esta investigación. Para la selección del corpus de análisis atravesamos dos etapas. En la primera, identificamos todas las películas españolas, coproducidas o no, estrenadas entre los años 1999 y 2012, teniendo como base los datos disponibles en el catálogo de películas del ICAA - Instituto de la Cinematografía y de las Artes Audiovisuales del Gobierno de España. La elección del periodo de selección se debe a que nuestra investigación está vinculada al Proyecto Internacional de Investigación (I+D+i) titulado Desplazamientos, emergencias y nuevos sujetos sociales en el cine español, financiado por el gobierno de España. El grupo de investigación que interviene en dicho proyecto prepara un volumen donde se estudian las películas realizadas entre los años 1999 y 2012 para poder contemplar las distintas variables del cine español en circunstancias de cambio de siglo y de la primera década del nuevo milenio en relación con la realidad social, política y cultural. Por otro lado, teniendo en cuenta que la llegada de inmigrantes a España comienza a principios de los 90, desde 1999 a 2012 en el cine español se ha consolidado ya el personaje del inmigrante, como reflejo de una sociedad pluricultural y multiétnica.

A partir de ese primer universo, que totalizan 1.019 filmes, seleccionamos todas las películas ficcionales - excluyendo los documentales y películas de animación - que específicamente contenian en su reparto actrices de origen latinoamericano. La búsqueda de esa información 
se ha realizado manualmente a través de una consulta en los sitios Filmaffinity e IMDb (Internet Movie Database). Todas las películas recogidas han sido individualmente consultadas y, cuando era identificada la presencia de una o más actrices -protagonistas o secundarias- oriundas de países latinoamericanos, la producción era seleccionada para formar parte del corpus de análisis, dando como resultado un total de 188 películas. Es importante subrayar que no es posible afirmar con certidumbre que todas las películas que contengan actrices latinoamericanas estrenadas en ese periodo hayan sido seleccionadas, considerando que pueden existir personajes de menor importancia para la trama que no siempre son recogidos en las fichas de reparto. Aun así, consideramos que el corpus es representativo del universo propuesto.

Para esta etapa empírica optamos por el método Análisis de Contenido presentado por Bardin (2009). Epistemológicamente, el método permite un abordaje cuantitativo y cualitativo del contenido de la comunicación, en este caso de relatos cinematográficos. En los análisis cuantitativos, el foco se concentra en la frecuencia con que surgen determinadas características del contenido y en elementos variables (como temáticas, por ejemplo) previa y sistemáticamente codificados. De acuerdo con Bardin, "el análisis de contenido aparece como un conjunto de técnicas de análisis de las comunicaciones que utiliza procedimientos sistemáticos y objetivos de descripción del contenido de los mensajes" (2009, p.38. Traducción propia). Para su aplicación, la autora sugiere la división en etapas: pre-análisis (definición del corpus); exploración del material; tratamiento de los resultados; inferencia e interpretación.

Al optar por este método como instrumento de investigación nos direccionamos a una investigación cuantitativa, pero con una interpretación cualitativa de los datos, ya que la regularidad de aparición es considerada el resultado más significativo. Asi, enfocamos determinadas características del contenido del corpus y su frecuencia, definidas en relación a los objetivos de este estudio: investigar cómo se construye la presencia de la mujer inmigrante latinoamericana en el cine español, durante el periodo definido para análisis.

Como temáticas o categorias definimos las siguientes: Coproducción con Latinoamérica; Protagonismo de las actrices; Nacionalidad; Franja etaria; Género de las películas y Temáticas centrales. Para la discusión de resultados presentaremos gráficos con datos cuantitativos, así como cruces de categorias que contribuyan a alcanzar los objetivos expuestos. En etapas posteriores a esta investigación se profundizará en los hallazgos presentados con enfoques específicos y con recortes del corpus inicial. Entendemos que la relevancia de los resultados cuantitativos propuestos, originarios de un corpus extenso y representativo, se concentra especialmente en perfilar la mujer inmigrante latinoamericana en el cine español, presentando un panorama del fenómeno en cuestión que potencialmente se plantee como base para otros cuestionamientos acerca de su representación, puntuando lagunas, silenciamientos, así como nuevas formas de resistencia y visibilidad.

\section{Entre datos y discusiones}

Para la organización de la discusión proponemos cruzar los datos que provienen de diferentes temáticas para elucidar cómo se construye la presencia de la mujer inmigrante latinoamericana en el cine español durante el periodo elegido. Algunos de los resultados empíricos no responden propiamente a la pregunta central que orienta esta investigación, pero se muestran interesantes para su contextualización. Así, iniciaremos nuestros resultados descubriendo sus puntos clave.

\subsection{Las coproducciones}

Al pre-categorizar coproducciones con paises latinoamericanos para análisis, pretendiamos averiguar si las relaciones comerciales entre el cine español y dichos países implicaban mayor presencia de ciertas nacionalidades en detrimento de otras, influyendo en la aparición de personajes inmigrantes con determinadas características, en diferentes aspectos. De hecho, esa hipótesis se ha confirmado y, sobre el tema, ahondaremos en 
el próximo punto. Aqui trataremos brevemente de las coproducciones como forma de fomentar la producción cinematográfica, basándonos en datos cuantitativos. De las 188 películas que componen el corpus de esta investigación, 74 (39.36\%) son coproducciones entre España y países Latinoamericanos, distribuidas de la siguiente forma:

Figura 1 - Países con los que España coproduce películas entre 1999 y 2012

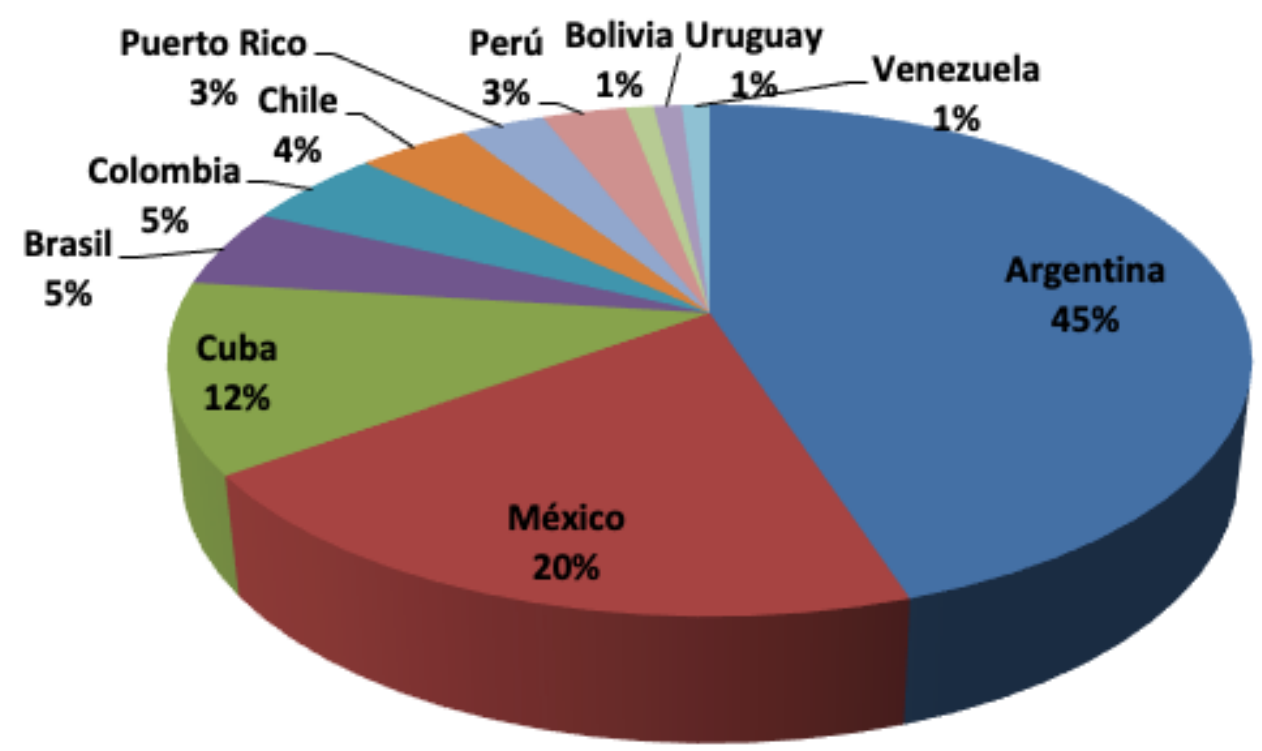

Fuente: Elaboración de las autoras (2021).

Las coproducciones constituyen una interesante posibilidad para la difusión de producciones nacionales en mercados internacionales, más allá de beneficios económicos asociados a la financiación, ya que al coproducir se amplía el circuito de comercialización y exhibición de obras cinematográficas. Seguramente existan otros aspectos socioeconómicos que intervienen en este escenario y, aunque merezcan tratarse, no lo haremos en este artículo, a tenor de los objetivos propuestos.

En el contexto de las coproducciones, según Escala (2006) y Montalbán (2015), España es el mayor aliado de Latinoamérica, al compartir el mismo idioma con casi todos los paises y poseer lazos culturales comunes. Si miramos los resultados del gráfico expuesto, percibimos que un $45 \%$ de todas las películas españolas del corpus coproducidas con Latinoamérica se realizan con Argentina, seguida de México, con el 20\%, y Cuba, con el 12\%. Para Escala (2006), el caso de Argentina es el más emblemático, ya que las coproducciones con España han significado el reconocimiento a nivel global de directores/ directoras y actores/actrices de este país, desarrollando un verdadero star system argentino, con resultados y expectativas a largo plazo. Por tanto, más allá de las relaciones culturales y lingüisticas, para algunos países ese vínculo es más fácil que para otros.

\subsection{Géneros y temáticas centrales}

A lo largo de la etapa empírica, además de las coproducciones, identificamos en el corpus los géneros de las películas, así como las temáticas centrales de las tramas, utilizando como base el catálogo de ICAA y los portales de Filmaffinity e IMDb. En cuanto a géneros cinematográficos, el drama es el más frecuente y, sumado a la comedia dramática, representa más de la mitad de todas las obras cinematográficas del corpus. Es cierto que aspectos relacionados con el costo de las 
producciones influyen en los resultados. Según Rossini (2016), el predominio de películas ficcionales de bajo presupuesto ha marcado la industria cinematográfica brasileña de forma contundente, con equipos reducidos que ficcionalizaban lo real. La autora afirma que la mayor pluralidad de géneros y temáticas es un fenómeno reciente en Brasil. Considerando las semejanzas, esa es una realidad de todo el cine latinoamericano, salvo excepciones. En ese sentido, el predominio del drama en los resultados es bastante previsible, especialmente en las coproducciones, y aún más asociado a los temas más frecuentes: Romance (amor, desamor, infidelidad), presente en 56 películas; Familia, identificada en 31 y Delitos (asesinato, atraco, maltrato, marginalidad, drogas, etc.), tema de 30 peliculas.

Entendemos que los aspectos económicos mencionados son bastante relevantes, pero hay otros factores que se suman y posiblemente nos ayuden a explicar la prevalencia del drama y temas de la vida real cotidiana en esas producciones. El corpus de la investigación está constituido por películas que presentan mujeres extranjeras oriundas de Latinoamérica en su reparto, y en las 188 películas seleccionadas del corpus identificamos 292 personajes con estas características, interpretando roles protagonistas o coprotagonistas en un $50 \%$ de los casos. Estos datos son importantes porque resultan diferenciadores, ya que el protagonismo femenino no es una realidad en el cine español. De acuerdo con el Estudio sobre la presencia de la mujer en las producciones españolas de ficción (2014-2016), solo el $38 \%$ de los personajes del cine español en este periodo son mujeres, y cuando hablamos de protagonismo, las actrices consiguieron solo el 34\% de estos papeles (AISGE, 2017). Así, la muestra que compone nuestro corpus -o parte considerable de ella- posiciona a la mujer en el centro del relato. Eso podria ayudar a explicar por qué no solo el drama es la temática que domina esas producciones, sino que también se den temas frecuentes como la familia y el romance.

Kamita (2017), cuando retoma los estudios feministas sobre el cine, discute sus reivindicaciones en diferentes momentos históricos. La autora apunta que todavia no está superada la representación de la mujer a partir de su identidad sexual determinada por una supuesta naturaleza esencialista. En ese contexto, la esfera reproductiva (que asegura la continuidad de la especie y de la vida), asociada al matrimonio y al cuidado de la familia, es socialmente asignada a la mujer, en una desigual división sexual del trabajo (HIRATA; KERGOAT, 2007). En una construcción cultural conservadora y tradicional se esperaría que la mujer protagonizara temáticas centradas en el romance -incluyendo aquí el desamor y los problemas amorosos- así como los conflictos familiares. Además, como asevera Ferreira (2018), el melodrama se caracteriza por la frecuencia de temas de apego emocional con función moralizadora y refleja valores burgueses del siglo XIX, donde la familia ocupa un lugar central en el orden patriarcal.

También nos llama la atención la frecuencia de relatos que reflejan delitos y marginalidad, incluyendo aquí los más diversos tipos de infracciones. Siguiendo la lógica anteriormente discutida, esa presencia no se justificaria. Aunque no podamos calificar todos los roles de las mujeres inmigrantes en esas tramas, por la extensión del corpus, algunos ejemplos se muestran ilustrativos. Encontramos personajes como el de Lola (la actriz colombiana Flora Martinez), que junto a su novio Alfredo sobrevive mediante atracos a hombres incautos que la suben en el coche y se dejan seducir por ella, en la película Tuya siempre (2007) de Manuel Lombardero. O como Fausta (Magaly Solier, peruana) de La teta asustada (Claudia Llosa, 2009), hija de una victima de violación y malos tratos que le dejaron marcas profundas. Otro caso es el de Zulema (Micaela Nevárez, venezolana) en la película Princesas (FERNANDO LEÓN, 2005), una prostituta ilegal extorsionada por un funcionario.

Sobre los datos cuantitativos, los números sugieren que al género se suman otras relaciones de poder que posicionan a esas mujeres en un grupo específico, posiblemente marginal - o como delincuentes o como víctimas -, al menos en parte 
de esas líneas de acción. Un estudio centrado en la representación de esas mujeres -teniendo como base las películas del corpus cuya temática se centra en la marginalidad- está en proceso y sus resultados serán oportunamente publicados.

En los epigrafes que siguen analizaremos aspectos distintivos de la mujer inmigrante en el corpus, a partir de los resultados cuantitativos.

\section{Nacionalidad y otras variables asociadas}

Para entender un poco más profundamente la imagen de la inmigrante latinoamericana en el cine español a partir de la nacionalidad, aislamos las películas de producción únicamente española y contabilizamos las nacionalidades de actrices de países latinoamericanos que han actuado en ellas. Asi evidenciamos que en esa parte del corpus no existe una motivación contractual que influya en la presencia de estas actrices. Los resultados componen el gráfico que sigue:

Figura 2 - Personajes femeninos en películas no coproducidas por nacionalidad

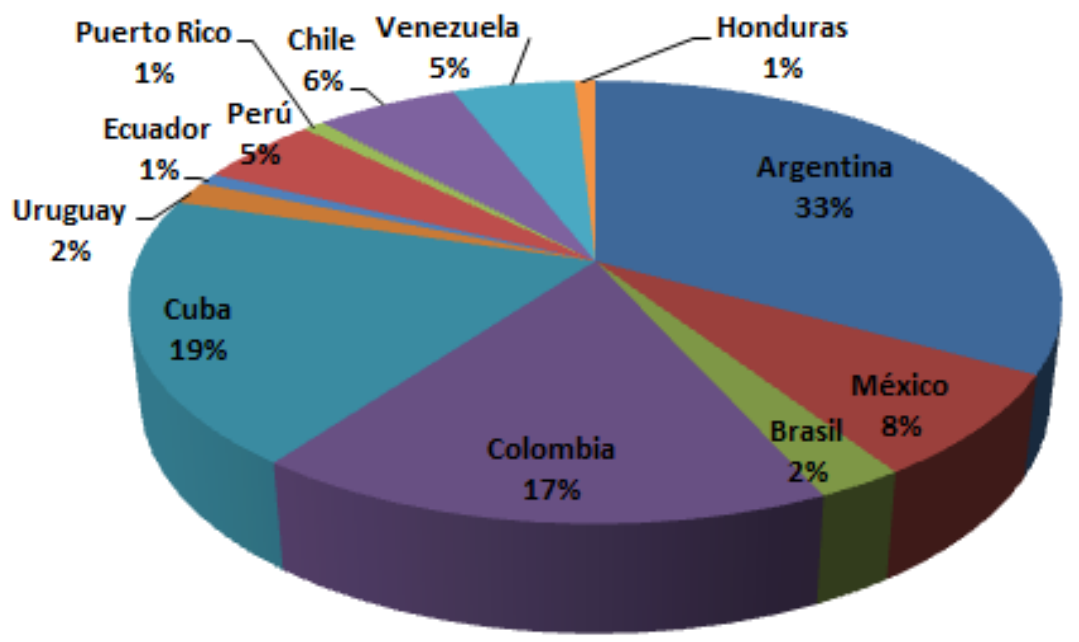

Fuente: Elaboración de las autoras (2021).

\subsection{Mujeres Argentinas: ¿continuidad del colonialismo de género en el cine?}

Al observar los datos, identificamos que las argentinas siguen ocupando el primer puesto entre las latinoamericanas, seguidas de las cubanas y las colombianas. Aquí, ciertos aspectos sociales que emergen de los números merecen nuestra atención. Al hablar de la "mujer latinoamericana" tropezamos con una serie de estereotipos de raices socioculturales imbricadas en el racismo y sexismo, que tienden, incluso, a excluir de este grupo a la mayoría de las mujeres argentinas, aunque su nacionalidad las posicione como latinoamericanas. Los aspectos étnicos parecen sobreponerse a los geográficos, y las diferencias o hibridismos presentes en las zonas de contacto que identificamos como Latinoamérica se caracterizan, como afirma Gloria Anzaldúa (2000), por un escrutinio geopolítico de los mestizajes.

Aqui existe un encuentro teórico y empírico que merece más atención. Después de los años 80, el feminismo, o parte de él - antes prioritariamente eurocentrista y estadounidense -, se entrecruza con el pos-colonialismo, generando conclusiones prácticas y teóricas para las mujeres bajo el impacto del colonialismo, tanto del pasado como del presente: "Tanto los movimientos feministas como los anticolonialistas tienen que cuestionar las ideas dominantes de historia y representación, ya que la cultura es vista como un campo de conflicto entre opresores y oprimidos, donde el lenguaje puede ser una herramienta de dominación" (BALLESTRIN, 2017, p. 1037). 
Si bien esta concepción no es capaz de identificar las diferencias y compensar las brechas y omisiones marcadas por la clase, raza y sexualidad, también es cierto que la idea de geopolitización del debate feminista inaugura la mirada hacia un grupo de mujeres unidas por opresiones propias de quienes han sido colonizadas. Sobre esa combinación, Anzaldúa (2000) afirma que se trata de una interrelación entre etnia y geopolítica. La autora se dirige a sus compañeras de lucha como hermanas y proclama:

Los peligros que enfrentamos como mujeres de color no son los mismos que los de las mujeres blancas, aunque tengamos demasiado en común. No tenemos mucho que perder, nunca tuvimos privilegios. Me gustaria llamar a los peligros 'obstáculos', pero eso sería mentira. No podemos trascender los peligros, no podemos superarlos. Debemos pasar por eso y no esperar una repetición (ANZALDÚA, 2000, p. 229, traducción propia).

La carta de Anzaldúa demuestra con maestría toda la rebeldía de la mujer del "tercer mundo" que borra y desequilibra "las confortables imágenes estereotipadas" (2000, p. 230) que se construyen de la mestiza. En ese sentido, Lugones (2008) explicita que al utilizar el término "mujeres de color" - también presente en las escrituras de Anzaldúa - su intención es referirse a la frase adoptada por mujeres dependientes, víctimas de dominaciones múltiples en Estados Unidos.

\begin{abstract}
'Mujer de Color' no apunta a una identidad que separa, sino a una coalición orgánica entre mujeres indigenas, mestizas, mulatas, negras: cherokees, puertorriqueñas, sioux, chicanas, mexicanas, pueblo, en fin, toda la trama compleja de las víctimas de la colonialidad del género. Pero tramando no como víctimas, sino como protagonistas de un feminismo decolonial. La coalición es una coalición abierta, con una intensa interacción intercultural (LUGONES, 2008, p. 75).
\end{abstract}

Si los hibridismos marcan el perfil de la mujer latinoamericana, con toda la complejidad que eso significa, nos llama la atención el hecho de que las actrices argentinas hayan sido las preferidas para su representación (o ausencia de ella). Pertenecer al grupo racial hegemónico posiciona mujeres en espacios de poder privile- giados, exactamente los privilegios que Anzadúa (2000) menciona en su carta. Lo que el corpus aporta para esta discusión, en datos cuantitativos, se refiere a la presencia masiva de mujeres de nacionalidad argentina en el cine español, al menos en el periodo estudiado. Argentina es el país más caucasiano entre los latinoamericanos. Según el último censo (INDEC, 2010), solamente 2,4\% de la población residente en Argentina es de indigenas o descendientes de pueblos originarios y $0,37 \%$ de afrodescendientes.

En el cine español, es la mujer argentina con rasgos europeos la que más abunda en nuestro corpus, corroborando el mantenimiento del pensamiento hegemónico. Esta afirmación se basa en el hecho de que todas las actrices argentinas que actuaron al menos en tres películas del corpus son de etnia blanca. Los nombres más frecuentes fueron Cecilia Roth, que entre 1999 y 2005 interpretó seis personajes inmigrantes, Ágatha Fresco, Betiana Blum y Viviana Saccone, cada una con tres personajes en el corpus. Los tipos de personajes que encarnan estas actrices son variados, aunque en el caso de Cecilia Roth tiende a interpretar mujeres con dramáticas carencias emocionales como la muerte del hijo, la desaparición repentina del marido o la falta de pareja (Todo sobre mi madre - Pedro Almodóvar, 1999, La hija del canibal - Antonio Serrano, 2003 - y Otros días vendrán - Eduard Cortés, 2005). En cambio, Betiana Blum se mueve más hacia el territorio de la comedia con personajes optimistas y emprendedores, como en los filmes Esa maldita costilla (Juan José Jusid, 1999) o Reinas (Manuel Gómez Pereira, 2005). Es curioso, pero en ninguno de los casos se observa un papel más ligado a la inmigrante de origen humilde que llega a España con la idea de encontrar perspectivas de trabajo más estables que en su país de origen (que si se da en otras nacionalidades), a pesar de que Argentina haya enfrentado una fuerte crisis económica a fines de la década de 90 y principio de los años 2000 (CASTELLANI; SCHORR, 2004). Además, el ámbito laboral en el que se desarrolla la actividad de esas mujeres no está relacionado con cuidados, trabajo doméstico o 
de servicios. El caso de Betiana Blum en Reinas ofrece la imagen de una mujer que ha perdido su negocio en Argentina pero que tiene la posibilidad de instalarse en España como empresaria, aunque la excusa es ir a España a la boda de su hijo (con trabajo estable y bien remunerado y con relaciones de pareja y sociales de alto nivel económico). Así, concluimos que más allá de cuestiones económicas, relaciones de poder basadas en raza/etnia se muestran relevantes.

\subsection{Cuba, la atracción del exotismo}

Siguiendo con la interpretación de los datos, después de Argentina, Cuba mantiene el segundo puesto de nuestro estudio (Figura 2) y nos parece pertinente acercarnos a caracteristicas que podrían justificar esta posición. El interés que Cuba genera es notable en el cine. Su historia política como símbolo de resistencia contrahegemónico ha atraído muchas miradas. En nuestro corpus encontramos cuatro películas con "Habana" en el título y una con "Cuba", la mayor parte de ellas producidas exclusivamente por España. Más allá, tras una simple búsqueda en el sitio Filmaffinity, se encuentran 65 casos de películas con la palabra "Cuba" en el título y 40 con la palabra "Habana".

La popularidad de las actrices cubanas en España está presente en nuestros resultados y algunos rostros concretos se repiten con frecuencia. Encabeza la lista Yoima Valdés, presente en cinco películas del corpus, seguida de Mirtha Ibarra, Laura Ramos y Marilyn Torres, con personajes en cuatro películas del corpus cada una. Entre las cubanas, en contraposición con las argentinas, impera la pluralidad étnico-racial, así como en la población cubana, aunque la raza blanca prevalezca. Según la Oficina de Estadística e información de Cuba, en el último Censo (ONEI, 2012), el 64,1\% de las personas que residen en Cuba se autodeclararon blancas, el 26,6\% mestizas y el 9,3\% negras. No podemos estudiar aquí el modo en que esa diversidad está representada en el cine español y los posibles estereotipos asociados, pero simplemente su presencia con papeles importantes, en alguna medida, significa la existencia de mujeres de etnias no hegemónicas en la pantalla. En coherencia con las cifras del censo, de las cuatro actrices con mayor número de papeles en nuestro corpus únicamente hay una actriz negra (Marilyn Torres). Esta actriz solo tiene un papel relevante en la película Flores de otro mundo (Iciar Bollaín, 1999), ya que en los otros tres filmes (Una palabra tuya -Ángeles González Sinde, 2008-, Fuga de cerebros -Manel Santisteban, 2009- y Mentiras y gordas - Albacete y Menkes, 2009-), posee un papel secundario. En la pelicula de Bollain interpreta a una inmigrante que sale del país para vivir con un español (José Sancho). No se siente enamorada, pero aprovecha el encaprichamiento del maduro español para poder salir de Cuba. Recibe humillaciones, malos tratos físicos y cosificación por parte del personaje masculino que paga los gastos de su pasaje y que, por ese motivo, se considera su dueño. Otras actrices afrocubanas presentes en nuestro corpus, pero con menor número de papeles, son Daisy Granados, Adela Legrá, Yunet Guerra, Marieta Sanchez, Ma Teresa Pina o Laura de la Uz.

\subsection{Las estrellas colombianas}

Cuando consideramos películas exclusivamente españolas, la tercera nacionalidad más frecuente es la colombiana, con $17 \%$ de las producciones. Es justamente la popularidad de las colombianas lo que las posiciona entre las nacionalidades más comunes en el corpus. Cuatro nombres están entre los más cotizados: Ana Isabel Velásquez, Angie Cepeda, Flora Martínez y Martina Garcia. En nuestro corpus hay escasa presencia de actrices afrocolombianas e indigenas, aunque aparece Lina Forero, personaje de reparto en el filme No habrá paz para los malvados (ENRIQUE URBIZU, 2011). Es curioso notar que las cuatro actrices nombradas arriba rondan edades parecidas (todas nacieron entre 1974 y 1981). Y casualmente (o no) la actriz Martina García interpreta el papel de sirvienta en dos películas (La mosquitera - Agustí Vila, 2010 - y Rabia - Sebastián Cordero, 2009), un rol poco habitual entre las actrices argentinas (si entre peruanas o ecuatorianas).

Al optar por puntuar diferencias entre pueblos latinoamericanos a partir de los datos cuantita- 
tivos sobre las mujeres de estas nacionalidades que ocupan espacios de mayor o menor protagonismo en el cine español, decidimos cruzar variables que desestabilizan los esencialismos basados en un pensamiento que considera "género" una categoría indivisible, como ya hemos abordado. Entendemos que las diferencias existen y se expresan en la representación simbólica, así como en la vida práctica de las mujeres.

Es cierto que el ideario que sostiene las disputas de poder en Latinoamérica es el resultado - como en todas las políticas contrahegemónicas - de un proceso de identificación de reclamos conectado a su historia de colonización, lo que seguramente sirve de unión para estos países. En el enfoque de las estructuras de poder basadas en cuestiones de género, aunque la participación de "mestizas", negras, criollas e indigenas en la lucha contra el colonialismo haya sido amplia, no ha estado debidamente reconocida.

El racismo heredado de la Colonia no permitió que las mujeres se reconocieran como tales, sino que las relegó a categorías ligadas tanto a la clase de procedencia como a la pertenencia étnica: blancas, mestizas, indias y negras no compartian cosmovisiones ni espacios sociales, sólo el maltrato masculino que, en el caso de las últimas, sumaba la violencia machista y la violencia racista (GARGALLO, 2007).

En consonancia, Lugones (2008, p.99) asevera la necesidad de una mirada detallada en "los procesos del sistema de género colonial/moderno en su larga duración, entramados en la colonialidad del poder hasta el presente". Ese movimiento nos permitiría desenmascarar la organización de lo social y reanudar el compromiso de tornar visible la violencia de género sistemáticamente racializada, así como el reconocimiento de la fundamental lucha de las mujeres no blancas "por la integridad comunal en una dirección liberatoria".

Considerando el objeto de esta investigación - el cine español y la presencia de mujeres inmigrantes latinoamericanas - es imposible ignorar que el poscolonialismo resulte un tema incómodo. Todo su recorrido requiere una mirada crítica que posiciona al colonizador y a las colonizadas en esferas de disputa y relaciones de poder. Al representar inmigrantes de países colonizados, hay una tendencia, según Teixeira (2014), de exponer una dimensión abstracta que no respeta las especificidades culturales en todas sus incoherencias y contradicciones formativas. Es decir, los discursos fílmicos, en este caso los producidos por españoles, suelen generalizar la cultura del "otro" o "ousider", desvalorizando lo que Bhabha (1998) nombra de "in-between", un espacio transicional de las designaciones supuestamente fijas de identidad proveniente de las interacciones simbólicas que abre posibilidades para la hibridación cultural.

En su estudio, Teixeira ha analizado la producción de la alteridad migratoria en la filmografía española y ha concluido que se examinan temas como la xenofobia y la manifestación social de la intolerancia, especialmente a partir de los años 90, en perspectivas más o menos críticas a la retórica migratoria proveniente del discurso "nosotros - otros" perpetrado por los medios de comunicación tradicionales. Para Teixeira, "el ámbito más difícil de la experiencia de la alteridad, dentro de lo que tiene de más necesario y paradojalmente más impedido, es la posibilidad de dominio y autogestión de su propia presencia" (2014, p. 49).

\section{Cuestiones etarias}

Una de las preguntas planteadas al inicio de la investigación estaba relacionada con la edad de las mujeres presentes en las películas (actrices y, por lo tanto, personajes). Los asuntos concernientes a la edad de la mujer pueden implicar conclusiones interesantes, por lo que esta variable fue uno de los parámetros elegidos para el análisis. Nos planteamos tres franjas diferentes, buscando homogeneizar la investigación y recabar datos que permitieran una utilidad posterior:

Figura 3 - Categoría Rango de edad

Rango de edad A: mujeres entre 18 y 30 años Rango de edad B: mujeres entre 31 y 59 años Rango de edad C: mujeres mayores de 60 años 
Así, teniendo en cuenta estos tres rangos de edad, los resultados del análisis del total de las 188 películas contempladas, incluyendo a todas las actrices de origen latinoamericano y los 292 papeles de mujeres inmigrantes encontrados, fueron los siguientes:

Figura 4 - Edad de los personajes femeninos de las películas del corpus

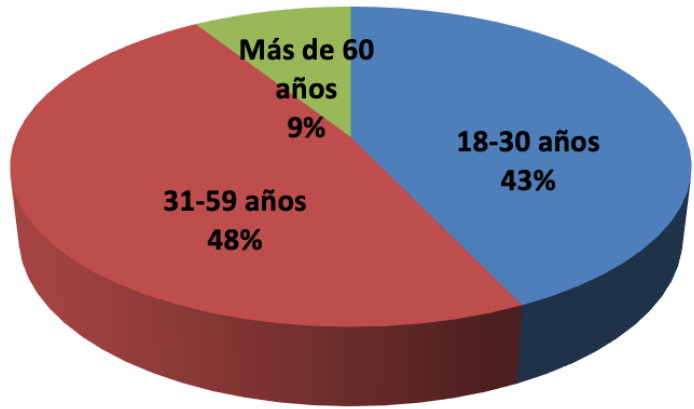

Fuente: Elaboración de las autoras (2021).

No existe demasiada diferencia entre los dos primeros rangos de edad, relacionados con la juventud y la madurez de la mujer: por un lado 125 personajes de 18-30 años (42.8\%) y 140 personajes de 31-50 años (47.9\%). En cambio, resulta muy llamativo que la franja de mayores de 60 años solo tenga un $9.2 \%$ de presencia en la muestra, con tan solo 27 personajes.

Este dato indica claramente que la representación de la mujer latinoamericana dentro del cine español de estos años se inclina hacia un perfil de mujer joven o madura, desinteresándose por mujeres envejecientes de más de 60 años.

Si analizamos los rangos de edad de los personajes protagonistas y coprotagonistas (es decir, desechando los personajes secundarios), el interés por la mujer joven se hace todavía más evidente y las mujeres envejecientes resultan aún más excluidas, pues solamente hay 8 personajes femeninos protagonistas con más de 60 años en el total de la muestra.
Figura 5 - Edad de los personajes femeninos protagonistas y coprotagonistas de las películas del corpus

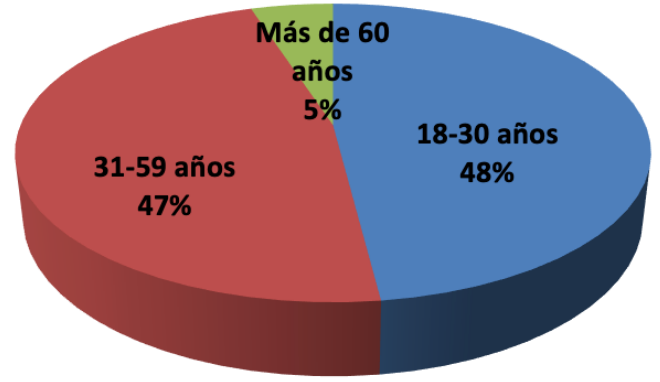

Fuente: Elaboración de las autoras (2021).

En ese sentido, está en desarrollo un estudio especifico, partiendo de la investigación que da lugar a este artículo, cuyo objetivo se centra en entender cómo se constituye la representación de las escasas mujeres mayores que componen el corpus, tanto protagonistas y coprotagonistas como secundarias. Sus resultados, todavía incipientes, se muestran interesantes por la pluralidad de personajes, lo que de antemano nos hace pensar que las posibles vivencias acotadas podrian ser ampliadas en términos cuantitativos y, así, mucho más representativos. Además de los roles esperados de abuelas y madres de familia, responsables del cuidado, mantenimiento y estabilidad en el hogar (como en Seres queridos-Pelegri y Harari, 2004-, El cuerno de la abundancia-Juan Carlos Tabio, 2008, cuidadoras (De tu ventana a la mía-Paula Ortiz, 2011, o mujeres frágiles o enfermas (9o millas -Francisco Rodríguez Fernández, 2005, Sexo por compasión-Laura Mañá, 2000), encontramos mujeres mayores libres, independientes, alegres, llenas de vida, emprendedoras y activas en la búsqueda de la felicidad y el amor (Ciudad en celo-Hernán Gaffet, 2006-, Reinas-Manuel Gómez Pereira, 2005, Esa maldita costilla-Juan José Jusid, 1999). 
La discriminación por motivos de edad es un fenómeno que ha dado lugar a varios términos en el territorio de la ciencia y la reflexión social. Se denomina en inglés ageism y todavía no se ha acuñado un término univoco en castellano. La Comisión Europea lo denomina edaísmo, pero los estudios de Ciencias Sociales utilizan también vocablos como etarismo, edadismo, gerontofobia e incluso viejismo. A pesar de las confusiones con el término, el concepto está bien consensuado: se trata de la discriminación y estereotipación de determinados colectivos o personas por motivos de la edad, argumentando asi creencias y valores que justifican su discriminación. Si tenemos en cuenta etarismo y mujeres tenemos dos focos diferentes de discriminación unidos que afectan a un ámbito poblacional muy amplio. Hay que tener en cuenta que en España - y en otros muchos paises- hay una feminización de la vejez: las mujeres son mayoritarias, superando en un 32\% a los hombres, una cifra que va en aumento conforme más avanzada es la edad (ABELLÁN GARCÍA et al., 2019). Como señala Bolen (2003, p. 14), "para un patriarcado orientado sobre todo hacia la juventud, convertirse en una mujer mayor es convertirse en alguien invisible, en una no-entidad". Esta invisibilidad se confirma y reafirma por la ausencia de mujeres mayores en los medios de comunicación en general y del cine en particular, siendo "raras y escasas las historias que se centran en el protagonismo de una mujer madura o anciana, normalmente encasillada en papeles secundarios, o utilizada como elemento puramente ornamental para que personajes más jóvenes tengan un contrapunto" (GORDILLO, 2010, p. 100).

Siendo el valor de las mujeres históricamente determinado por su potencial reproductivo (HIRATA; KERGOAT, 2007), la mujer considerada bella y virtuosa se convierte en una cuyo cuerpo es reconocido como saludable y capaz de generar nuevas vidas. La belleza femenina, por lo tanto, está vinculada al posicionamiento de las mujeres dentro del grupo de edad llamado edad fértil, o, de otra manera, en su desempeño en la emulación de proximidad de este grupo de edad.
Resulta especialmente significativo uno de los datos encontrados en relación con una de las actrices latinoamericanas. Cecilia Roth (Argentina, 1956) aparece en nuestro corpus en seis películas diferentes. Sin embargo, de esas seis películas hay cinco concentradas de 1999 a 2002 (cuando la actriz tenía de 43 a 46 años) y una en 2005 (49). Sin embargo, una vez que la actriz cumple 50 años deja de aparecer en las peliculas analizadas y, observando su filmografia, puede verse que las intervenciones en el cine son mucho menos frecuentes que en momentos anteriores de su carrera.

Existen diferentes cuestiones de intersección entre los datos obtenidos del presente estudio que abren otras líneas de investigación, pero que por las limitaciones del artículo resulta inviable desarrollarlas aqui: los tipos de personajes que interpretan las mujeres mayores, las esferas de acción a las que se circunscriben y las relaciones entre nacionalidad, etnicidad y mujer envejeciente, por ejemplo. Es cierto, como concluye Pacheco (2013) en su investigación empírica acerca de la afectividad de la mujer negra, que las relaciones de género y raza/etnia adquieren significados distintos cuando son accionados los marcadores sociales de edad/generación, los cuales también son determinados por contextos culturales e históricos, en este caso el de la inmigración.

\section{Conclusiones}

Como objetivo principal de la investigación marcábamos el foco de interés en la presencia de la mujer latinoamericana como personaje inmigrante en el cine español a principios de siglo XXI, más concretamente en el periodo entre 1999 y 2012. A partir de aqui constatamos su aparición en el $18.4 \%$ de las películas de ficción que se produjeron en este periodo temporal (lo que significa 188 filmes de los 1019 estrenados, entre producciones y coproducciones). En este número tan considerable de largometrajes se identificaron 292 personajes femeninos. Si tenemos en cuenta solamente las producciones meramente españolas (es decir, excluyendo 
coproducciones), nos encontramos con un 33\% de actrices argentinas, un $19 \%$ cubanas y un $17 \%$ colombianas. Queda confirmado entonces que el prototipo que representa la mujer argentina con rasgos europeos es la que más veces representa a la mujer latinoamericana en el cine español del periodo, con las consecuencias que este hecho puede alcanzar al reflexionar sobre la Argentina como el país más caucásico de Latinoamérica y este grupo racial el que se sitúa en el centro del pensamiento hegemónico.

La paradoja que este resultado pone en evidencia se relaciona con la disyunción entre nacionalidad y etnia. La imagen de la "mujer latinoamericana" se sostiene en el mestizaje, así, aunque la nacionalidad argentina posicione esos personajes cinematográficos como inmigrantes latinoamericanas, aspectos étnicos parecen sobreponerse a los geopolíticos y los aparta de este rol, al menos en parte.

En nuestros análisis identificamos que las principales temáticas de los filmes analizados son el romance, la familia, o sea, la vida cotidiana, dentro del drama o la comedia dramática. Aunque también se presentan numerosos argumentos relacionados con delitos y marginalidad, temas recurrentes cuando se habla de inmigración. Queda abierta otra línea de estudio para verificar en qué medida esas mujeres protagonistas o coprotagonistas están relacionadas con el delito, si ocupan el papel de víctima o de sujeto agresor, investigación en proceso de análisis de un corpus reducido y ajustado, y cuyos resultados serán oportunamente publicados.

De los 292 personajes de mujeres latinoamericanas, la mitad ocupaban el rol de protagonistas/ coprotagonistas y la otra mitad eran personajes secundarios. Sorprende el número tan representativo de mujeres oriundas de Latinoamérica situadas en un lugar destacado en los argumentos de esas producciones (140 en total). Sin embargo, al cruzar el dato con otras variables del análisis, observamos que este papel se restringe a actrices con características especificas no solamente a aspectos étnicos y raciales. Entre las variables más llamativas destaca el hecho de que las mujeres envejecientes (mayores de 60 años) solamente interpretan un 5\% de papeles importantes en las tramas de las películas analizadas, mientras que el $48 \%$ de las protagonistas tienen entre 18 y 30 años. Así pues, podemos considerar que la mujer latinoamericana envejeciente es una figura invisibilizada de nuestro estudio.

Consideramos que la presencia de la mujer latinoamericana en el cine español atiende a una lógica hegemónica de visibilidad controlada. Al indagar acerca de la emergencia de una proliferación de la diferencia estructurada en esa dinámica, Hall (2003) afirma que "lo que sustituye la invisibilidad es una especie de visibilidad cuidadosamente regulada y segregada" (Hall, 2003, p.321.Traducción propia). Si mujeres inmigrantes latinoamericanas pasan a ocupar las narrativas del cine español y a garantizar una presencia identitaria de resistencia antes poco visible, como pudimos comprobar en nuestra investigación, nos queda por delante comprender en qué medida su representación significa desplazamientos de las disposiciones de poder y rupturas del pensamiento colonialista, ya que su presencia nos lleva a interpretar que estamos lejos de la pluralidad.

\section{Referencias}

AISGE. Estudio sobre la presencia de la mujer en las producciones españolas de ficción (2014-2016) 2017. Disponible en: https://www.aisge.es/media/ multimedia/ficheros/788.pdf. Aceso en: 15 ene. 2021

ABELLÁN GARCÍA, Antonio et al. Un perfil de las personas mayores en España. Indicadores estadisticos básicos. Informes Envejecimiento en red, Madrid, n. 22, mar. 2019. Disponible en: http://envejecimiento.csic es/documentos/documentos/enred-indicadoresbasicos2019.pdf . Aceso en: 20 mar. 2021.

ANZALDÚA, Gloria. Falando em línguas: uma carta para as mulheres escritoras do Terceiro Mundo. Revista Estudos Feministas, Florianópolis, v. 8, n.1, p. 229-236, 2000.

BALLESTRIN, Luciana. Feminismos Subalternos. Revista Estudos Feministas, Florianópolis, v. 25, n. 3, p. 1035-1054, 2017.

BARDIN, Laurence. Análise de Conteúdo. Lisboa: Edições 70, 2009.

BHABHA, Homi. O local da cultura. Belo Horizonte: Editora da UFMG, 1998. 
BOLE, Jean. Las diosas de la mujer madura. Arquetipos femeninos a partir de los cincuenta. Barcelona: Kairós, 2003

CARNEIRA, Sueli. Construção do outro como não-ser como fundamento do ser. 2005. Tesis (Doctorado en Educación) - Programa de Pós-Graduação em Educação, Universidade de São Paulo, São Paulo, 2005.

CASTELLANI, Ana; SCHORR, Martín. Argentina: convertibilidad, crisis de acumulación y disputas en el interior del bloque de poder económico. CDC, Caracas, v. 21, n. 57, p. 55-82, 2004.

CASTIELO, Chema. Los parias de la tierra. Inmigrantes en el cine español. Madrid: Talasa Ediciones, 2005.

CAVIELLES-LLAMAS, Ivan. De Otros a Nosotros: El Cine Español sobre Inmigración y su Camino hacia una Visión Pluricultural de España (1990-2007). 2008. Tesis (Maestría) - University of Massachusetts, 2008.

COLLINS, Patricia Hill. Black feminist thought: knowledge, consciousness, and the politics of empowerment. New York: Taylor \& Francis e-Library, 2002.

ESCALA, Nella. Cine latinoamericano en el mercado español. Revista Chasqui, Quito, n. 93, p. 54-61, 2006.

FERREIRA, Ceiça. Reflexões sobre a "mulher", o olhar e a questão racial na teoria feminista do cinema. Revista Famecos, Porto Alegre, v. 25, n. 1, 2018.

FIGUEIREDO, Angela. Epistemologia insubmissa feminista negra decolonial. Tempo e Argumento, Florianópolis, v. 12, n. 29, e0102, p. 1-24, 2020.

GARGALLO, Francesca. Feminismo Latinoamericano. Revista Venezolana de Estudios de la Mujer, Caracas, V. 12, n. 28,2007

GORDILLO, Inmaculada (2006): El diálogo intercultural en el cine español contemporáneo: entre el estereotipo y el etnocentrismo. Revista Comunicación, Sevilla, $n$. 4. p. 207-222, 2006.

GORDILLO, Inmaculada . La mujer "envejeciente": silencios, estereotipos y miradas en el cine de la primera década del siglo XXI. In: SANGRO, Pedro; PLAZA, Juan $F$. (ed.). La representación de las mujeres en el cine y la televisión contemporáneos. Barcelona: Laertes, 2010. p. 97-116.

HABERMAS, Jürgen. Teoria do agir comunicativo: Sobre a Crítica da Razão Funcionalista. São Paulo: WMF Martins Fontes, 1981. v. 2.

HALL, Stuart. Da diáspora: Identidade e mediações culturais. Belo Horizonte: Editora UFMG/Representação da UNESCO no Brasil, 2003

HIRATA, Helena; KERGOAT, Danièle. Novas Configurações da Divisão Sexual do Trabalho. Cadernos de Pesquisa, São Paulo, v. 132, n. 37, p. 595-609, 2007.

INDEC. Instituto Nacional de Estadisticas y Censos, República Argentina, 2010. Censo 2010. Disponible en: https://www.indec.gob.ar/indec/web/Nivel4-Tema-2-41-135. Aceso en: 30 mar. 2021.
KAMITA, Rosana Cássia. Relações de gênero no cinema: contestação e resistência. Revista Estudos Feministas. Florianópolis, v. 25, n. 3, p. 1393-1404, 2017.

LUGONES, Maria. Colonialidad y género. Tabula Rasa, Bogotá, n. 9. p. 73-101, 2008.

MONTALBÁN, Paco. Un recorrido por las coproducciones hispano-argentinas en los últimos veinte años. La critica, 2015. Disponible en: http://www.lacriticanyc. com/coproducir-para-triunfar. Aceso en: 15 feb. 2021.

MOYANO, Eduardo. La memoria escondida. Emigración y cine. Madrid: Tabla Rasa, 2005

MUÑIZ, Carlos et al. La inmigración latinoamericana en los contenidos informativos. Un estudio sobre las noticias de prensa y televisión españolas. Revista Palabra Clave, Chía (Colombia), v. 10, n. 2, p. 75-92, 2007.

NAIBOGLU, Gozde. Towards an audiovisual archaeology of reproduction: gestures of migrant sex work in contemporary European cinema. Feminist Media Study, [S. I.], v. 18, n. 3, p. 411-423, 2017.

ONEI. Oficina Nacional de Estadistica e información de Cuba, Censo, 2012. ONEI. Disponible en: www.one.cu/ publicaciones/cepde/cpv2012/20131107resumenadelantado/Tablas/4.pdf. Aceso en: 5 feb. 2021.

PACHECO, Ana Claudia. Mulher negra: Afetividade e solidão. Salvador: Edufba, 2013.

ROSSINI, Miriam et al. Tendências do Cinema Brasileiro contemporâneo: modelos de produção e de representação. Revista Sessões do Imaginário, Porto Alegre, v. 21, n. 35, p. 2-11, 2016.

SANTAOLALLA, Isabel. Los "Otros". Etnicidad y "raza" en el cine español contemporáneo. Madrid-Zaragoza: Ocho y Medio y Prensas Universitarias de Zaragoza, 2005.

TEIXEIRA, Rafael. Cinema, identidade e memória: A produção da alteridade migratória na cinematografia espanhola desde La aldea maldita, 1930 a Princesas, 2005. Revista Chasqui, Quito, n. 125, p. 43-50, 2014.

\section{Renata Barreto Malta}

Doutora em Comunicação Social pela Universidade Metodista de São Paulo, em São Bernardo do Campo, SP, Brasil com pós-doutorado na Universidad de Sevilla, Espanha; mestre em Comunicação pela Universidade Estadual Paulista (UNESP), em Bauru, SP, Brasil. Professora efetiva da Universidade Federal de Sergipe (UFS) e do Programa de Pós-Graduação em Comunicação (PPGCOM) da UFS, em São Cristóvão, SE, Brasil.

\section{Inmaculada Gordillo}

Doutora em Comunicación Audiovisual pela Universidad de Sevilla, Espanha. Profesora da Facultad de Comunicación da Universidad de Sevilla, España. 


\section{Endereços para correspondencia}

\section{Renata Barreto Malta}

Universidade Federal de Sergipe

Departamento de Comunicação Social

Av. Marechal Rondon, $\mathrm{s} / \mathrm{n}$

Jardim Rosa Elze, 49100-000

São Cristóvão, SE, Brasil

\section{Inmaculada Gordillo}

Universidad de Sevilla, Facultad de Comunicación

Avda. Américo Vespucio $\mathrm{s} / \mathrm{n}$

La Cartuja, C.P 41092

Sevilla, Espanha

Os textos deste artigo foram revisados pela Poá Comunicação e submetidos para validação do autor antes da publicação. 